\title{
PERBANDINGAN METODE ASM, STEPPING STONE DAN METODE MODI PADA BIAYA ANGKUT TRANSPORTASI (Kasus Studi: Data Pendistribusian Raskin Perum Bulog Divre Kalimantan Barat Tahun 2018 Pada Bulan Januari-September)
}

\author{
Fitri, Helmi, Mariatul Kiftiah
}

\section{INTISARI}

\begin{abstract}
Dalam mendistribusikan barang ke berbagai tujuan sebagai salah satu bagian dari operasional perusahaan, tentu membutuhkan biaya transportasi yang besar. Perencanaan yang matang diperlukan agar biaya transportasi yang dikeluarkan seminimal mungkin. Perum Bulog Divre Kalimantan Barat sebagai pelaksana program Raskin untuk beberapa wilayah di Kalimantan Barat yaitu Divre Kota Pontianak, Subdivre Singkawang, Subdivre Ketapang, Subdivre Sintang, Subdivre Sanggau, dan Subdivre Putussibau dibawah koordinasi Divre Kalimantan Barat mengeluarkan dana yang cukup besar untuk kegiatan pendistribusian. Pengeluaran biaya angkut transportasi yang dikeluarkan Perum Bulog Divre Kalimantan Barat sebesar Rp. 2.236.337.070,-. Metode transportasi yang digunakan untuk memecahkan permasalahan transportasi pada penelitian ini adalah metode ASM, metode Stepping Stone dan metode Modi. Penelitian ini bertujuan untuk membandingkan metode ASM, metode Stepping Stone dan metode Modi dalam meminumumkan biaya angkut transportasi pendistribusian Raskin Perum Bulog Divre Kalimantan Barat. Langkah-langkah dalam pemecahan pencarian solusi optimal pada masalah transportasi ini dengan membuat tabel transportasi dari data yang sudah dikumpulkan. Mencari solusi optimal menggunakan metode ASM, metode Stepping Stone dan metode Modi. Berdasarkan hasil perhitungan diperoleh besarnya biaya angkut transportasi menggunakan metode ASM, Stepping Stone dan metode Modi menghasilkan biaya transportasi yang sama sebesar Rp. 2.046.604.020,-, sehingga menghemat biaya pendistribusian sebesar Rp. 189.733.050,- atau sama dengan $8,48 \%$ berkurangnya dari biaya distribusi yang dikeluarkan Perum Bulog. Perusahaan dapat menghemat biaya dengan cara pengalokasian yang tepat.
\end{abstract}

Kata kunci: Riset Operasi, Metode Vogel, Raskin

\section{PENDAHULUAN}

Perum Bulog Divre Kalimantan Barat sebagai pelaksana program Raskin untuk beberapa wilayah di Kalimantan Barat yaitu Divre Kota Pontianak, Subdivre Singkawang, Subdivre Ketapang, Subdivre Sintang, Subdivre Sanggau, dan Subdivre Putussibau dibawah koordinasi Divre Kalimantan Barat mengeluarkan dana yang cukup besar untuk kegiatan pendistribusian. Salah satu faktor penyebabnya adalah besarnya biaya angkut beban distribusi Raskin ke setiap tujuan yang dikeluarkan. Oleh karena itu diperlukan perencanaan yang matang untuk meminimumkan biaya pendistribusian Raskin yang dikeluarkan adalah seoptimal mungkin.

Salah satu metode yang dapat digunakan untuk mengoptimalkan biaya distribusi adalah dengan metode transportasi [1]. Metode transportasi terdiri dari dua langkah utama, yaitu pencarian solusi awal dan pencarian solusi optimal. Untuk mencari solusi awal antara lain metode Pojok Barat Laut, Metode Biaya Terkecil, dan metode VAM (Vogel's Approximation Method). Metode Stepping Stone dan metode Modi digunakan untuk pencarian solusi optimal dari penyelesaian awal yang telah diperoleh sebelumnya menggunakan ketiga metode di atas. Seiring perkembangan waktu, metode untuk menyelesaikan masalah transportasi bisa diselesaikan secara langsung tanpa mencari solusi awal. Beberapa metode langsung yang telah berhasil dikembangkan diantaranya metode ASM, metode Zero Neigbourning, metode Zero Suffix, metode Zero Point, metode Exponential Approarch. 
Permasalahan pada penelitian ini adalah membandingkan hasil biaya pendistribusian Raskin Perum Bulog Divre Kalimantan Barat Tahun 2018 pada bulan Januari-September sesuai dengan persediaan dan permintaan dari perusahaan atau anak perusahaan. Penulisan ini dilakukan dengan menggumpulkan data yang terdiri dari data pendistribusian Raskin yang meliputi lokasi gudang serta biaya transportasi pendistribusian, jumlah permintaan Raskin, dan jumlah persediaan Raskin. Kemudian membuat tabel dari data yang telah ada. Mencari solusi optimal menggunakan metode ASM, metode Stepping Stone, dan metode Modi. Penelitian ini bertujuan untuk membandingkan metode ASM, metode Stepping Stone dan Metode Modi untuk meminimumkan biaya angkut transportasi pendistribusian Raskin Perum Bulog Divre Kalimantan Barat.

\section{METODE TRANSPORTASI}

Metode transportasi merupakan suatu metode yang digunakan untuk mengoptimalkan biaya pengangkutan dari berbagai daerah sumber menuju berbagai daerah tujuan. Metode transportasi juga dapat digunakan untuk perencanaan produksi [2]. Gambaran umum masalah transportasi dapat dilihat pada Tabel 1.

Tabel 1. Gambaran Umum Masalah Transportasi

\begin{tabular}{|c|c|c|c|c|c|}
\hline \multirow{2}{*}{$\operatorname{Sumber}\left(S_{i}\right)$} & \multicolumn{4}{|c|}{ Tujuan $\left(D_{j}\right)$} & \multirow{2}{*}{ Persediaan $\left(a_{i}\right)$} \\
\hline & $D_{1}$ & $D_{2}$ & $\ldots$ & $D_{n}$ & \\
\hline$S_{1}$ & $\begin{array}{l}c_{11} \\
x_{11} \\
\end{array}$ & $\begin{array}{c}c_{12} \\
x_{12} \\
\end{array}$ & \begin{tabular}{|l|}
$\ldots$ \\
$\ldots$ \\
\end{tabular} & \begin{tabular}{|c|}
$c_{1 n}$ \\
$x_{1 n}$ \\
\end{tabular} & $a_{1}$ \\
\hline$\vdots$ & $\begin{array}{c}\ldots \\
\vdots \\
\vdots\end{array}$ & $\begin{array}{c}\ldots \\
\vdots \\
\end{array}$ & $\begin{array}{c}\ldots \\
\vdots \\
\end{array}$ & \begin{tabular}{|l|}
$\ldots$ \\
$\quad \vdots$ \\
\end{tabular} & $\vdots$ \\
\hline$S_{m}$ & $\begin{array}{l}c_{m 1} \\
x_{m 1} \\
\end{array}$ & $\frac{c_{m 2}}{x_{m 2}}$ & \begin{tabular}{|c|}
$\ldots$ \\
$\ldots$ \\
\end{tabular} & \begin{tabular}{|c|}
$c_{m n}$ \\
$x_{m n}$ \\
\end{tabular} & $a_{m}$ \\
\hline$b_{j}$ & $b_{1}$ & $b_{2}$ & $\ldots$ & $b_{n}$ & \\
\hline
\end{tabular}

Sumber: Rangkuti, 2013

Keterangan :

a) $S_{i}$ adalah sumber ke $i, i=1,2,3, \ldots, m$

b) $D_{j}$ adalah tujuan ke $j, j=1,2,3, \ldots, n$

c) $a_{i}$ adalah persediaan ke $i, i=1,2,3, \ldots, m$

d) $b_{j}$ adalah permintaan ke $j, j=1,2,3, \ldots, n$

e) $c_{i j}$ adalah biaya transportasi per unit barang dari sumber $i$ ke tujuan $j, i=1,2,3, \ldots, m$, $j=1,2,3, \ldots, n$

f) $x_{i j}$ adalah banyak unit yang diangkut dari sumber $i$ ke tujuan $j, i=1,2,3, \ldots, m, j=1,2,3, \ldots, n$

Berdasarkan Tabel 1 dapat disusun model matematika sebagai berikut :

Meminimalkan : $Z=c_{1} x_{1}+c_{2} x_{2}+\ldots+c_{m n} x_{m n}$

dengan kendala : $\sum_{j=1}^{m} x_{i j}=a_{i}, i=1,2, \ldots, m$

$\sum_{j=1}^{n} x_{i j}=b_{j}, j=1,2, \ldots, n$

$x_{i j} \geq 0$, untuk semua $i$ dan $j$

\section{METODE ASM}

Metode ASM merupakan metode langsung untuk menyelesaikan masalah transportasi dengan menitikberatkan pada sel hasil reduksi baris dan kolom. Langkah-langkah penyelesaian transportasi menggunakan metode ASM menurut [3] sebagai berikut :

1. Membuat tabel transportasi.

2. Mengurangi nilai tiap baris pada tabel transportasi dengan nilai minimum tiap baris. Kemudian mengurangi nilai tiap kolom dengan nilai minimum tiap kolom. 
3. Memilih nilai nol pada baris dan kolom. Misalkan yang dipilih $(i, j)$, hitung jumlah nol (kecuali yang sudah dipilih) pada baris ke $i$ dan kolom ke $j$. Kemudian memilih nol selanjutnya dan menghitung jumlah nol sesuai baris dan kolom dengan cara yang sama. Diperlakukan untuk baris dan kolom biaya.

4. Memilih nol dengan jumlah nol minimum dari hasil perhitungan langkah 3 dan memenuhi jumlah maksimum yang memungkinkan pada sel tersebut. Jika terjadi jika terjadi lebih dari satu untuk beberapa nol dari langkah 3, pilih salah satu nol dari beberapa nol tersebut kemudian mengalokasikan jumlah yang mungkin untuk sel tersebut.

5. Menghapus baris atau kolom dimana persediaan maksimum data telah habis dan permintaan sudah terpenuhi.

6. Mengecek apakah hasil perhitungan barisan dan kolom terdapat minimal satu nilai nol terdapat pada baris dan kolom? Jika tidak, maka kembali kelangkah 2, selain itu melanjutkan kelangkah 7.

7. Mengulangi langkah 3 dan 6 kecuali semua permintaan terpenuhi dan semua persediaan telah habis.

\section{METODE STEPPING STONE}

Metode Stepping Stone merupakan langkah lanjutan dari metode awal untuk mendapatkan solusi optimal. Metode Stepping Stone merubah alokasi produk untuk mendapatkan alokasi produksi yang optimal menggunakan cara coba-coba. Langkah-langkah metode Stepping Stone sebagai berikut [4]:

1. Isi tabel awal dengan metode solusi awal.

2. Pilih sebarang sel kosong untuk diisi dengan syarat akan membentuk loop yang berakhir dan berawal pada sel kosong, dimana sel yang masuk hanyalah sel yang akan diisi.

3. Beri tanda plus (+) pada sel kosong, tempatkan secara bergantian tanda plus (+) dan tanda minus (-) pada setiap kotak pada jalur tertutup yang baru saja dilalui.

4. Hitunglah indeks perbaikan dengan menambahkkan biaya unit yang ditemukan setiap kotak berisi tanda plus (+) dilanjutkan dengan mengurangi biaya unit pada setiap kotak berisi tanda minus (-).

5. Ulangi langkah 3 hingga 4 sampai semua indeks perbaikan untuk semua kotak yang tidak terpakai sudah dihitung. Jika semua indeks yang dihitung lebih besar atau sama dengan nol, maka solusi optimal tercapai. Jika belum, dapat terus ditingkatkan untuk mengurangi biaya pengiriman total.

\section{METODE MODI}

Metode Modi merupakan perkembangan dari metode Stepping Stone, karena penentuan segi tempat sel kosong yang bisa menghemat biaya dilakukan dengan prosedur yang lebih pasti dan tepat. Adapun langkah-langkah metode Modi sebagai berikut [4]:

1. Penentuan sel masuk

Untuk setiap sel basis, hitung $u_{i}+v_{j}=c_{i j}$.

$u_{i}$ menunjukkan baris ke $i, v_{j}$ menunjukkan kolom ke $j$ dan $c_{i j}$ adalah biaya pada sel $i j$, karena jumlah variabel yang tidak diketahui $u_{i}$ dan $v_{j}$ lebih banyak dibandingkan jumlah persamaan yang dibentuk, maka salah satu variabel diasumsikan bernilai 0 . Untuk setiap sel non basis, hitung $\overline{c_{l j}}=u_{i}+v_{j}-c_{i j} \cdot \overline{c_{l j}}$ adalah biaya yang baru yang akan dicari.

2. Penentuan sel keluar. Penetuan sel keluar dilakukan menggunakan loop tertutup. Awal dan akhir loop adalah sel masuk.

3. Periksa apakah sudah optimal. Syarat optimal untuk meminimalkan adalah jika $\overline{C_{i j}} \leq 0$.

\section{HASIL DAN PEMBAHASAN}

Berdasarkan data dari Perum Bulog Divre Kalimantan Barat yang meliputi data kapasitas persediaan, permintaan dan banyaknya pendistribusian Raskin yang dikeluarkan dari gudang 1 (Serdam) dan gudang 2 (Wajo Hulu) kesetiap tujuan dapat dilihat dalam bentuk Tabel 2 sebagai berikut: 
Tabel 2. Distribusi Raskin (Kg) setiap Bulan dari Dua Gudang ke setiap tujuan pada Divre Kalimantan Barat Tahun 2018 pada Bulan Januari-September

\begin{tabular}{|c|c|c|c|c|c|c|c|}
\hline \multirow[b]{2}{*}{ Sumber $\left(S_{i}\right)$} & \multicolumn{6}{|c|}{ Tujuan $\left(D_{j}\right)$} & \multirow{2}{*}{$\begin{array}{l}\text { Persediaan } \\
\qquad\left(a_{i}\right)\end{array}$} \\
\hline & $D_{1}$ & $D_{2}$ & $D_{3}$ & $D_{4}$ & $D_{5}$ & $D_{6}$ & \\
\hline Gudang 1 & 377.375 & 207.705 & 180.930 & 180.580 & 94.590 & 64.150 & 1.105 .330 \\
\hline Gudang 2 & 377.375 & 207.705 & 180.930 & 180.580 & 94.590 & 64.150 & 1.105 .330 \\
\hline $\operatorname{Permintaan}\left(b_{j}\right)$ & 754.750 & 415.410 & 361.860 & 361.160 & 189.180 & 128.300 & 2.210 .660 \\
\hline
\end{tabular}

Biaya distribusi yang dikeluarkan oleh Perum Bulog dari gudang setiap tujuan yang diperoleh dari wawancara salah satu karyawan gudang dapat dibentuk dalam Tabel 3 sebagai berikut:

Tabel 3. Distribusi Raskin ( $\mathrm{Rp} / \mathrm{Kg}$ ) dari Dua Gudang ke setiap tujuan di Kalimantan Barat

\begin{tabular}{|c|c|c|}
\hline Sumber & Gedung Serdam & Gedung Wajo Hulu \\
\hline Tujuan & 87 & 174 \\
\hline Divre Kota Pontianak $\left(D_{1}\right)$ & 696 & 609 \\
\hline Subdivre Singkawang $\left(D_{2}\right)$ & 2088 & 2082 \\
\hline Subdivre Ketapang $\left(D_{3}\right)$ & 1392 & 1392 \\
\hline Subdivre Sintang $\left(D_{4}\right)$ & 783 & 870 \\
\hline Subdivre Sanggau $\left(D_{5}\right)$ & 2523 & 2610 \\
\hline Subdivre Putussibau $\left(D_{6}\right)$ & & \\
\hline
\end{tabular}

\section{Penyelesaian Menggunakan Metode ASM}

Hasil perhitungan dari metode ASM dapat disajikan dalam bentuk Tabel 4 sebagai berikut:

Tabel 4. Penyelesaian Menggunakan Metode ASM

\begin{tabular}{|c|c|c|c|c|c|c|c|}
\hline \multirow[b]{2}{*}{$\operatorname{Sumber}\left(S_{i}\right)$} & \multicolumn{6}{|c|}{ Tujuan $\left(D_{j}\right)$} & \multirow{2}{*}{$\begin{array}{l}\text { Persediaan } \\
\left(a_{i}\right)\end{array}$} \\
\hline & $D_{1}$ & $D_{2}$ & $D_{3}$ & $D_{4}$ & $D_{5}$ & $D_{6}$ & \\
\hline Gudang 1 & 754.750 & 0 & 0 & 33.100 & 189.180 & 128.300 & 0 \\
\hline Gudang 2 & 0 & 415.410 & 361.860 & 328.060 & 0 & 0 & 0 \\
\hline $\operatorname{Permintaan}\left(b_{j}\right)$ & 0 & 0 & 0 & 0 & 0 & 0 & 0 \\
\hline
\end{tabular}

Karena semua persediaan dan permintaan telah terpenuhi maka dapat dihitung menggunakan metode ASM pada tabel masalah transportasi tersebut yaitu sebesar

$$
\begin{aligned}
& Z=754.750(87)+415.410(609)+361.860(2082)+33.100(1392)+328.060(1392) \\
& \quad+189.180(783)+128.300(2523)=2.046 .604 .020
\end{aligned}
$$

Jadi biaya angkut transportasi menggunakan metode ASM sebesar Rp. 2.046.604.020,-. Maka pengalokasian pada Divre Pontianak dari gudang Serdam sebanyak $754.750 \mathrm{~kg}$, Subdivre Singkawang dari gudang Wajo Hulu sebanyak $415.410 \mathrm{~kg}$, Subdive Ketapang dari gudang Wajo Hulu sebanyak $361.860 \mathrm{~kg}$, Subdive Sintang dari gudang Serdam sebanyak $33.100 \mathrm{~kg}$ dan dari gudang Wajo Hulu sebanyak $328.060 \mathrm{~kg}$, Subdivre Sanggau dari gudang Serdam sebanyak $189.180 \mathrm{~kg}$, Subdivre Putussibau dari gudang Serdam sebanyak $128.300 \mathrm{~kg}$.

\section{Penyelesaian Menggunakan Metode Stepping Stone}

Hasil dari solusi awal metode Vogel dapat disajikan dalam bentuk Tabel 5 sebagai berikut:

\begin{tabular}{|c|c|c|c|c|c|c|c|}
\hline \multirow[t]{2}{*}{ Sumber $\left(S_{i}\right)$} & \multicolumn{6}{|c|}{ Tujuan $\left(D_{j}\right)$} & \multirow{2}{*}{$\begin{array}{l}\text { Persediaan } \\
\qquad\left(a_{i}\right)\end{array}$} \\
\hline & $D_{1}$ & $D_{2}$ & $D_{3}$ & $D_{4}$ & $D_{5}$ & $D_{6}$ & \\
\hline \multirow{2}{*}{ Gudang 1} & 754.750 & & & 161.400 & 189.180 & & \multirow{2}{*}{0} \\
\hline & 87 & 696 & 2088 & 1392 & 783 & 2523 & \\
\hline \multirow[b]{2}{*}{ Gudang 2} & & 415.410 & 361.860 & 199.760 & & 128.300 & \multirow[b]{2}{*}{0} \\
\hline & 174 & 609 & 2082 & 1392 & 870 & 2610 & \\
\hline Permintaan $\left(b_{j}\right)$ & 0 & 0 & 0 & 0 & 0 & 0 & 0 \\
\hline
\end{tabular}

Tabel 5. Penyelesaian Awal Menggunakan Metode Vogel 
Karena persediaan dan permintaan telah habis maka dapat dihitung hasil menggunakan metode Vogel sebagai berikut:

$$
\begin{aligned}
Z= & 754.750(87)+415.410(609)+361.860(2082)+161.400(1392)+199.760(1392) \\
& +189.180(783)+128.300(2610)=2.046 .965 .880
\end{aligned}
$$

Hasil perhitungan dari metode Stepping Stone solusi optimal dapat disajikan dalam bentuk Tabel 6 sebagai berikut:

\begin{tabular}{|c|c|c|c|c|c|c|c|}
\hline \multirow{2}{*}{$\begin{array}{l}\text { Sumber } \\
\left(S_{i}\right)\end{array}$} & \multicolumn{6}{|c|}{ Tujuan $\left(D_{j}\right)$} & \multirow{2}{*}{$\begin{array}{c}\text { Persediaan } \\
\left(a_{i}\right)\end{array}$} \\
\hline & $D_{1}$ & $D_{2}$ & $D_{3}$ & $D_{4}$ & $D_{5}$ & $D_{6}$ & \\
\hline \multirow{2}{*}{ Gudang 1} & 754.750 & & & 33.100 & 189.180 & 128.300 & \multirow[b]{2}{*}{0} \\
\hline & 87 & 696 & 2088 & 1392 & 783 & 2523 & \\
\hline \multirow[b]{2}{*}{ Gudang 2} & & 415.410 & 361.860 & 328.060 & & & \multirow[b]{2}{*}{0} \\
\hline & 174 & 609 & 2082 & 1392 & 870 & 2610 & \\
\hline Permintaan $\left(b_{j}\right)$ & 0 & 0 & 0 & 0 & 0 & 0 & 0 \\
\hline
\end{tabular}

Tabel 6 Tabel Perbaikan Metode Stepping Stone

Dari tabel pilih sel-sel yang kosong untuk mencari indeks perbaikan. Cari jalur terdekat (gerakannya harus horizontal atau vertikal) dari sel yang kosong melalui pijakan sel kosong itu kembali ke sel kosong semula. Tanda $(+)$ dan $(-)$ muncul bergantian pada tiap sudut sel dari jalur terpendek, dimulai dengan tanda $(+)$ pada sel kosong. Tanda putaran searah jarum jam. Hitunglah indeks perbaikan dengan cara menambahkan biaya unit yang ditemukan pada setiap kotak yang berisi tanda ( + ), dilanjutkan dengan mengurangi biaya unit pada setiap kotak yang berisi tanda ( - ). Semua indeks perbaikan untuk semua kotak sel kosong telah dihitung. Jika semua indeks yang dihitung lebih besar atau sama dengan nol, maka solusi optimal sudah tercapai. Jika tidak, maka solusi sekarang dapat ditingkatkan untuk mengurangi biaya pengiriman total.

Sel kosong:

$$
\begin{aligned}
& c_{12}=696-1392+1392-609=87 \\
& c_{13}=2088-1392+1392-2082=6 \\
& c_{21}=174-1392+1392-87=87 \\
& c_{25}=870-1392+1392-783=87 \\
& c_{26}=2610-1392+1392-2523=87
\end{aligned}
$$

Karena indeks perbaikan dari sel-sel lebih besar atau sama dengan nol maka solusi optimal telah tercapai. Jadi solusi optimal menggunakan metode Stepping Stone adalah

\begin{tabular}{|c|c|c|c|c|c|c|c|}
\hline \multirow{2}{*}{$\begin{array}{l}\text { Sumber } \\
\left(S_{i}\right)\end{array}$} & \multicolumn{6}{|c|}{ Tujuan $\left(D_{j}\right)$} & \multirow{2}{*}{$\begin{array}{l}\text { Persediaan } \\
\quad\left(a_{i}\right)\end{array}$} \\
\hline & $D_{1}$ & $D_{2}$ & $D_{3}$ & $D_{4}$ & $D_{5}$ & $D_{6}$ & \\
\hline \multirow{2}{*}{ Gudang 1} & 754.750 & & & 33.100 & 189.180 & 128.300 & \multirow{2}{*}{0} \\
\hline & 87 & 696 & 2088 & 1392 & 783 & 2523 & \\
\hline \multirow[b]{2}{*}{ Gudang 2} & & 415.410 & 361.860 & 328.060 & & & \multirow[b]{2}{*}{0} \\
\hline & 174 & 609 & 2082 & 1392 & 870 & 2610 & \\
\hline Permintaan $\left(b_{j}\right)$ & 0 & 0 & 0 & 0 & 0 & 0 & 0 \\
\hline
\end{tabular}

$$
\begin{aligned}
Z= & 754.750(87)+415.410(609)+361.860(2082)+33.100(1392)+328.060(1392) \\
& +189.180(783)+128.300(2523)=2.046 .604 .020
\end{aligned}
$$

Jadi biaya angkut transportasi menggunakan metode Stepping Stone sebesar Rp. 2.046.604.020,-. Maka pengalokasian pada metode ini sama seperti pengalokasian menggunakan metode ASM.

\section{Penyelesaian Menggunakan Metode Modi}

Hasil perhitungan dari metode Modi dapat disajikan dalam bentuk Tabel 7 sebagai berikut:

Tabel 7 Penyelesaian Menggunakan Metode Modi 
Untuk sel basis:

$$
\begin{aligned}
& u_{1}+v_{1}=87 \\
& u_{1}+v_{4}=1329 \\
& u_{1}+v_{5}=783 \\
& u_{1}+v_{6}=2523 \\
& u_{2}+v_{2}=609 \\
& u_{2}+v_{3}=2082 \\
& \mathrm{u}_{2}+v_{4}=1392 \\
& \mathrm{u}_{1}=0 \text { maka } \mathrm{v}_{1}=87, \mathrm{v}_{4}=1392, \mathrm{v}_{5}=783, \mathrm{v}_{6}=2523 \\
& \mathrm{u}_{2}=0 ; \mathrm{v}_{2}=609 ; \mathrm{v}_{3}=2082
\end{aligned}
$$

Untuk sel non basis: $\quad \overline{c_{12}}=u_{1}+v_{2}-c_{12}=0+699-696=0$

$$
\begin{aligned}
& \overline{\mathrm{c}_{13}}=\mathrm{u}_{1}+\mathrm{v}_{3}-\mathrm{c}_{13}=0+2082-2082=0 \\
& \overline{\mathrm{c}_{21}}=\mathrm{u}_{2}+\mathrm{v}_{1}-\mathrm{c}_{21}=0+87-174=-87 \\
& \overline{\mathrm{c}_{25}}=\mathrm{u}_{2}+\mathrm{v}_{5}-\mathrm{c}_{25}=0+783-870=-87 \\
& \overline{\mathrm{c}_{26}}=\mathrm{u}_{2}+\mathrm{v}_{6}-\mathrm{c}_{26}=0+2523-2610=-87
\end{aligned}
$$

Karena semua nilai $\overline{\mathrm{c}_{1 \mathrm{j}}}$ lebih kecil atau sama dengan nol, maka tabel sudah optimal.

$$
\begin{aligned}
Z= & 754.750(87)+415.410(609)+361.860(2082)+33.100(1392)+328.060(1392) \\
& +189.180(783)+128.300(2523)=2.046 .604 .020 .
\end{aligned}
$$

Jadi biaya angkut transportasi menggunakan metode Modi sebesar Rp. 2.046.604.020,-. Maka pengalokasian pada metode ini sama seperti pengalokasian menggunakan metode ASM dan Stepping Stone.

\section{PENUTUP}

Sesuai pada pembahasan dan hasil yang telah diuraikan sebelumnya, maka dapat disimpulkan:

1. Diperoleh biaya angkut transportasi pendistribusian Raskin Perum Bulog Divre Kalimantan Barat Tahun 2018 pada bulan Januari-September dengan metode ASM sebesar Rp. 2.046.604.020,-, dengan metode Stepping Stone sebesar Rp. 2.046.604.020,-, dan metode Modi biaya sebesar Rp. 2.046.604.020,-,

2. Berdasarkan data perusahaan menunjukkan total biaya yang dikeluarkan Perum Bulog Divre Kalimantan Barat Tahun 2018 pada bulan Januari-September adalah sebesar Rp. 2.236.337.070 untuk pendistribusian setiap bulannya.

3. Diperoleh solusi optimal pada biaya angkut pendistribusian Raskin dengan metode transportasi metode ASM, Stepping Stone dan Modi yang memiliki selisih biaya sebesar Rp. 189.733.050,atau sama dengan $8.48 \%$ berkurang dari biaya awal yang dikeluarkan Perum Bulog Divre Kalimantan Barat Tahun 2018 pada bulan Januari-September.

\section{DAFTAR PUSTAKA}

[1] Anugrah, M., Pengantar Riset Operasional, Gunadarma, Jakarta., 1993.

[2] Rangkuti, A., 7 Model Riset Operasi dan Aplikasinya, Brilian International, Surabaya. 2013.

[3] Quddoos, A.; Javaid, S. and Khalid, M.M., 2012, A New Method for Finnding an Optimal Solution for Transportasi Problem, IJCSE., 4: 1271 - 12.

[4] Siringoringo, H., Pemograman Linear., Graha Ilmu, Yogyakarta. 2005.

\section{FITRI}

HELMI

MARIATUL KIFTIAH
: Jurusan Matematika FMIPA UNTAN Pontianak fitriasnawi1122@gmail.com

: Jurusan Matematika FMIPA UNTAN, Pontianak helmi@math.untan.ac.id

: Jurusan Matematika FMIPA UNTAN, Pontianak kiftiahmariatul@math.untan.ac.id 